\title{
Fichte e Schelling em confronto - filosofia da reflexão ou não?
}

\author{
Francisco Prata Gaspar \\ francisco.gaspar81@gmail.com \\ Universidade de São Paulo (USP), São Paulo, SP.
}

Resumo: O objetivo do artigo é apresentar a discussão entre Fichte e Schelling em torno do conflito entre o idealismo transcendental da doutrina-da-ciência e a filosofia-da-natureza do Identitätssystem (sistema-daidentidade). Buscamos compreender, de um ponto de vista fichteano, se e em que medida é possível afirmar que a doutrina-da-ciência é uma filosofia da reflexão, tal como entendida por Schelling. Para tanto, em um primeiro momento, serão expostas as críticas de Schelling a Fichte, como ele progressivamente se afasta em relação à filosofia transcendental e busca consolidar a filosofia-da-natureza. Em um segundo momento, daremos a palavra a Fichte e a seus apontamentos críticos em relação ao projeto filosófico de uma filosofia-da-natureza. Nossa análise limitar-se-á à correspondência entre os dois filósofos e aos textos escritos em torno do período de ruptura entre eles. No caso de Fichte, indo até 1804.

Palavras-chave: Fichte; Schelling; doutrina-da-ciência, filosofia-da-natureza; absoluto; reflexão.

\section{Fichte and Schelling in confrontation - philosophy of reflection or not?}

\begin{abstract}
The aim of this paper is to present the discussion between Fichte and Schelling around the conflict between the transcendental idealism of the doctrine of science and the philosophy of nature of the Identitätssystem. We seek to understand, under a Fichtean point of view, if and how far it is possible to state that the doctrine of science consists in a philosophy of reflection, such as Schelling states. For this, at first, will be exposed the Schelling's critiques to Fichte, as the former progressively detaches himself from transcendental philosophy and consolidates a philosophy of nature. In a second moment, we will give the floor to Fichte's critical notes related to the philosophical project of a philosophy of nature. Our analysis will be restraint to the correspondence between those two philosophers and to the texts written around this period of rupture between them. In the case of Fichte, this goes until 1804 .
\end{abstract}

Keywords: Fichte; Schelling; doctrine of science, philosophy of nature; absolut; reflection.

\footnotetext{
É máxima do pensar claro e livre: sempre refletir. (...) a reflexão se impõe e, com ela, a dúvida. Se, em algum lugar e de modo correto, não se consegue afastar a dúvida, mas não se quer tê-la e, junto com ela, a reflexão que a produz, então: o que fazer? Meio heróico: aqui não se deve refletir, pois, do contrário, a realidade, que nós queremos ter pura e simplesmente, se perde; aqui se tem de fechar os olhos, pois quando se os abre surge a aparência, que ninguém aqui deve ver. (...) É desse método que se utiliza Schelling para manter em pé a sua natureza absoluta. Para ele, a doutrina-da-ciência é um sistema-dareflexão, e aí exatamente se encontra o erro. Em um tal proceder a natureza acaba em um mero aparecer. Como isso não deve acontecer, ele cuida, então, para não refletir - e isso é uma artimanha! - Quanta
} 
miséria! Não é no refletir que se encontra a dúvida, mas no fato de que a reflexão simula que é o eu que, enquanto indivíduo, pensa. Ao se afastar essa dúvida e se mostrar que é o saber único e necessário que ali pensa, então a reflexão não prejudicou a realidade, mas, antes, a estabeleceu correta, firme e claramente (FICHTE, 1962, GA II/12, p. 152).

No prefácio à Exposição do meu sistema da filosofia (1801), Schelling comenta, ainda que de modo alusivo e talvez um tanto temerário, a diferença existente entre a doutrina-da-ciência de Fichte e sua filosofia da identidade. Lemos ali: "Fichte poderia ter pensado o idealismo em uma significação totalmente subjetiva, eu, ao contrário, em uma significação objetiva; Fichte poderia, com o idealismo, se manter no ponto de vista da reflexão, eu, ao contrário, teria me colocado com o idealismo no ponto de vista da produção” (SCHELLING, 1976, I/10, p. 111)․ Tal juízo, todavia, não é ali algo abrupto, caprichoso ou arbitrário da parte de Schelling, mas o resultado de uma reflexão continuada acerca da natureza do idealismo transcendental e dos seus limites para a explicação do saber, reflexão que começa a tomar corpo, se não desde o início, certamente com os trabalhos de Schelling sobre a "filosofia-da-natureza". Ora, a despeito de certa temeridade inclusa no juízo de Schelling, a descrição da doutrina-da-ciência de Fichte como um "idealismo subjetivo", preso ao "ponto de vista da reflexão", fará escola. Sendo uma filosofia limitada especulativamente, já que refém de uma unilateralidade, ela será vista no mais das vezes como um momento de passagem entre Kant, de um lado, e Schelling e Hegel, de outro, e por isso não merecedora de uma atenção decisiva ${ }^{2}$. Mais que isso: mesmo no interior da Fichte Forschung, essa descrição da doutrinada-ciência funcionará quase como um modelo interpretativo das diferentes exposições da doutrina-daciência: Fichte teria defendido em seu período de Iena uma filosofia da subjetividade - um "idealismo subjetivo" - que, em um segundo momento, a partir das críticas de Schelling, teria sido superada por uma doutrina de um Absoluto real, chamado de Vida ou Ser absoluto, a partir do qual, diz-se, Fichte teria admitido uma realidade para além do saber, podendo até mesmo ser chamado de realista ${ }^{3}$. É assim que Schelling, em 1806, com a publicação de três escritos populares de Fichte, pôde falar em um sistema "melhorado" da doutrina-da-ciência, no qual Fichte teria adotado ideias do próprio Schelling de um Ser absoluto: "ele admitiu verdades que, antes, ele rejeitava" (SCHELLING, 1965, III, p. 622); Schelling até mesmo faz uma comparação de textos para mostrar esse suposto "roubo" (ibidem, p. 676-7)4.

Mas, afinal, seria a doutrina-da-ciência um idealismo subjetivo, presa ao ponto de vista da reflexão e da consciência, tal como a condena Schelling? Fichte não é dessa opinião: desde o primeiro momento, ele se opõe radicalmente às críticas de Schelling e ao seu projeto de uma filosofia-da-natureza como fundamento do idealismo transcendental, vendo na base deles, não há dúvida, uma leitura equivocada da filosofia transcendental em geral e da doutrina-da-ciência em particular. Nesse sentido, retomar o debate entre os dois filósofos parece se configurar como um momento privilegiado não só para, ao confrontar duas interpretações do idealismo transcendental, criticar uma determinada leitura que acabou por consagrar uma imagem da doutrina-da-ciência, como também para pôr em questão essa interpretação "evolutiva" do conjunto das exposições da filosofia de Fichte. Como pano de fundo, está em debate justamente a compreensão do conceito do "eu", tal como ele foi formulado por Fichte e criticamente exposto por Schelling. Para tanto, circunscreveremos nossas análises à correspondência entre os dois filósofos e aos textos escritos em torno do período de ruptura entre eles, indo até 1804. Mas, se é assim, é necessário, antes de tudo, elucidar o que Schelling entende por “filosofia da reflexão” e quais são, concretamente, suas críticas à doutrina-da-ciência enquanto saber de todo saber. Para isso, é preciso recuperar brevemente o modo como Schelling se relacionou historicamente com a doutrina-da-ciência. 
Se a relação de Schelling com a doutrina-da-ciência de Fichte é inicialmente de concordância, elogio e quase reiteração, com o tempo, ela passa a assumir um caráter crítico e de distanciamento em relação ao projeto de uma filosofia transcendental, que culminará não só em uma ruptura filosófica, como também pessoal. A rigor, esse distanciamento começa a tomar corpo com os trabalhos de Schelling sobre a filosofia-da-natureza ${ }^{5}$, nos quais o modo de explicação idealista para a natureza - tal como entendida por ele - passa a ser criticado e é proposto um outro modo de argumentação: a natureza não deve, pois, ser somente objeto do saber, mas também sujeito, ela deve ser sujeito-objeto, embora inconsciente e não para si, uma identidade de produtividade e produto, não mais algo meramente real, mas também ideal, quer dizer, real-ideal. É assim que na Introdução a um projeto de um sistema da filosofia-da-natureza (1799), Schelling já passa a descrever a inteligência como sinônimo tanto de espírito humano, como da própria natureza, dizendo que "há uma produtividade inconsciente, mas originariamente aparentada à consciente, cujo mero reflexo nós vemos na natureza" (SCHELLING, 1976, I/8, p. 29). Daí ser possível e mesmo necessário, para Schelling, fazer o caminho inverso ao do idealismo transcendental ("idealismo transcendental" na interpretação schellinguiana) e, ao invés de deduzir o real do ideal, deduzir o ideal a partir do real, exigindo, por consequência, uma ciência totalmente nova e complementar ao idealismo transcendental: a filosofia-da-natureza ${ }^{6}$. E até o Sistema do idealismo transcendental (1800), ambas as ciências são complementares, porque não há privilégio de nenhuma ciência sobre a outra, distinguindose somente pelas direções opostas de suas tarefas, e, contudo, porque ambas são igualmente necessárias no sistema do saber. Com o advento do sistema-da-identidade de Schelling, todavia, a filosofia-da-natureza não é mais uma ciência complementar ao idealismo transcendental, mas seu fundamento, cabendo a ela justamente a primazia no sistema do saber - é quando então as críticas de Schelling a Fichte tornar-se-ão explícitas e diretas.

Agora, é o próprio princípio da filosofia transcendental, o "eu", que não pode mais ser o pressuposto absoluto do saber, mas já é algo derivado e aparece como um produto do saber. De início, Schelling distingue "um idealismo da natureza e um idealismo do eu" e diz: "aquele é o originário, este, o derivado" (SCHELLING, 1976, I/10, p. 88). Quer dizer, a natureza, enquanto sujeito-objeto objetivo, é pensada como um momento do logos anterior ao advento do eu, enquanto sujeito-objeto subjetivo, e o que cabe à filosofia é deixar o subjetivo surgir a partir do objetivo - ou "expresso na linguagem filosófica superior, isso significa algo como: deixar o sujeito-objeto da consciência surgir do puro sujeito-objeto" (ibidem, p. 91). Ao contrário, se a doutrina-da-ciência já parte do sujeito-objeto subjetivo - o que Schelling chama também de "consciência consciente" -, ela parte da "potência suprema" do processo de desenvolvimento do puro sujeito-objeto e, daí, terá de contemplar tudo somente a partir desse seu ponto de vista derivado, o que já determina em definitivo o seu alcance especulativo. Afinal, ficar preso à "consciência consciente" significa ficar preso ao determinado estrato da reflexão, cujo momento é designado desde o Sistema do idealismo transcendental pela abstração transcendental de todo objetivo - e cujo ponto de vista é justamente aquele "da reflexão". É a partir dessa abstração que o eu, no interior da história da autoconsciência, aparece para si mesmo como uma consciência consciente, já que, ao se reconhecer como limitado pela intuição produtiva, que produziu (inconscientemente) os objetos, tem diante de si a objetividade, o mundo objetivo, sobre o qual, nessa medida, ele pode atuar conscientemente de acordo com seu querer - e por isso, aliás, a abstração é a ação pela qual o eu passa do domínio teórico (o inconsciente e objetivo) para o domínio prático (consciente e subjetivo), o que significa: quando objetivo e subjetivo se separam e constituem-se 
para o eu como dois domínios distintos: "pela própria abstração, diz Schelling, a inteligência torna-se algo diferente do seu produzir, o qual, porém, justamente por isso não pode mais aparecer como um agir, mas apenas como um produzido" (SCHELLING, 1976, I/9, p. 204). Ora, como o único dado que a consciência tem para si, neste momento da história de sua formação, momento justamente da reflexão, é a sua atividade consciente, então, caso se queira construir um sistema da filosofia a partir dele, tudo será concebido a partir dessa atividade consciente, ou melhor, só será concebido o que essa atividade consciente pode explicar ou representar, o que significa objetificar, e o próprio mundo objetivo só poderá aparecer como o representado, que, por isso mesmo, não pode ser mais deduzido - está, pois, faticamente dado, e é impossível para a consciência pôr em questão o agir inconsciente anterior que produziu a objetividade, quer dizer, a natureza. Em termos especulativos, isso significa que uma filosofia presa ao ponto de vista da reflexão não é capaz de deduzir o saber e todos seus momentos geneticamente, mas, objetificando tudo, permanece presa ainda a objetos que ela admite faticamente, quer dizer, há produtos do próprio saber cuja produção ela não está em condições de explicar: ela toma como condição do saber - a consciência consciente - algo condicionado por ele próprio. Nisto, tal sistema da filosofia ainda permanece refém daquilo que Kant chamou de aparência transcendental: algo condicionado - produto do saber - é tomado como sua condição; na definição de Kant: "pode-se colocar toda aparência ao se tomar a condição subjetiva do pensamento pelo conhecimento do objeto" (KANT, 1968, IV, p. 396).

O filósofo que, no contexto do Sistema, aparece como expondo um sistema da filosofia a partir do ponto de vista da reflexão é, notadamente, Reinhold. Afinal, é ele quem procura fundar a sua "filosofia elementar" como ciência originária e fundamento das outras ciências (metafísica, lógica, moral e direito natural) sobre o princípio da representação, cuja sede é justamente a consciência ${ }^{7}$. Contra Reinhold, nesse momento, escreve Schelling: "para quem, por exemplo, em toda atividade do espírito, não há nada de inconsciente (Bewusstloses) e nenhuma região para além da região da consciência, este compreenderá tão pouco como a inteligência se esquece em seus produtos, quanto também como o artista pode se perder em sua obra. Para ele, não há nada a não ser o mero produzir moral ordinário, mas em parte alguma um produzir, no qual a necessidade está unificada com a liberdade" (SCHELLING, 1976, I/9, p. 125). Porque só admite o que entra na consciência através da representação, esse ponto de vista estará impossibilitado de conceber como pode surgir esse mundo objetivo para a inteligência, que, na verdade, é apenas um produto da sua atividade produtiva inconsciente, donde é levado a fixar as oposições entre teórico e prático, espírito e natureza, sem nunca pressentir que no fundamento dessa separação pode haver uma identidade. "Uma filosofia, que parte da consciência", continua Schelling no Sistema, "nunca poderá explicar aquela concordância, nem esta há de ser explicada sem a identidade originária, cujo princípio justamente se encontra necessariamente para além da consciência” (SCHELLING, 1976, I/9, p. 204).

Ora, se é verdade que, no Sistema do idealismo transcendental, a crítica de Schelling endereçada à filosofia presa ao ponto de vista da reflexão não é uma crítica a Fichte, porque até esse momento Fichte ainda não é visto como refém dele, trata-se, contudo, da mesma concepção do ponto de vista da reflexão, de modo que, com a emergência do sistema-da-identidade e a interpretação de que o "eu" da doutrina-da-ciência também é uma consciência consciente que teria diante de si um mundo objetivo (a natureza), o alvo da crítica amplia-se, incluindo agora também a doutrina-da-ciência: também esta é vista como fixando as oposições entre natureza e espírito, próprias ao ponto de vista da reflexão, e constituindo-se somente como um ponto de vista subjetivo do saber, já que reduz o saber e seus momentos à esfera do sujeitoobjeto subjetivo. Ignorando, portanto, o "passado transcendental"s do próprio eu, mas pressupondo 
todas as potências anteriores ao seu surgimento, a doutrina-da-ciência tem pressupostos fáticos que não pode questionar, e se ela pretende ser um saber genético de todo saber, anterior a todo saber de algo, o seu fracasso especulativo é patente. Como diz Schelling: "enquanto, no filosofar, eu me mantenho nessa potência, não posso contemplar nenhum outro objetivo a não ser no momento da sua entrada na consciência (...), nunca, porém, em seu surgir (Entstehen) originário, no momento do seu primeiro emergir (na atividade inconsciente) - ao chegar em minhas mãos, ele já percorreu todas as metamorfoses que são necessárias para se elevar à consciência" (SCHELLING, 1976, I/10, p. 89).

Ao contrário, se a filosofia quer expor o saber em todo seu sistema e no seu agir mais originário, enquanto puro sujeito-objeto e não mero sujeito-objeto subjetivo, apresentando assim todo produzir inconsciente e real presente na natureza, ela tem, evidentemente, de se retirar do ponto de vista subjetivo da reflexão e, com isso, elevar-se ao ponto de vista desse puro sujeito-objeto, no qual não há mais nenhuma intervenção subjetiva da consciência, mas é o próprio sujeito-objeto objetivo que expõe a si mesmo. Quer dizer, é preciso se elevar do ponto de vista subjetivo da consciência para aquele da própria razão, que Schelling, retomando a tradição metafísica, chamará de "ponto de vista do Absoluto": "não há filosofia a não ser do ponto de vista do Absoluto - nesta exposição não será levantada nenhuma dúvida quanto a isso: a razão é o Absoluto", "o ponto de vista da filosofia é o ponto de vista da razão, seu conhecimento é um conhecimento das coisas como elas são em si, isto é, na razão" (SCHELLING, 1976, I/10, p. 121). Para tanto, é preciso neutralizar esse elemento objetificador da consciência consciente, o que significa, conforme o Schelling do sistema-da-identidade: abstrair aquilo ao que o idealista transcendental permanece preso, a saber, o subjetivo ou o consciente da sua intuição intelectual, de tal modo que não se trate mais da "minha" intuição, mas da intuição do próprio sujeito-objeto, do próprio Absoluto. Com efeito, diz Schelling: "o que eu denomino natureza, não é, para mim, nada mais que o puramente objetivo da intuição intelectual, o puro sujeito-objeto, que aquele [o filósofo transcendental] põe $=\mathrm{eu}$, já que ele não faz a abstração do intuinte, que é, contudo, necessária, se uma filosofia puramente teórica, isto é, efetivamente teórica deve se realizar" (SCHELLING, 1976, I/10, p. 94). Daí que, ao pôr os pressupostos da doutrina-daciência e mostrar todos os atos da intuição produtiva anteriores à consciência e que fornecem o real de todo saber, a filosofia-da-natureza acaba por fundar a filosofia transcendental e possuir uma realidade puramente teórica - por isso, a primazia absoluta sobre o idealismo no interior do sistema do saber: a própria filosofia-da-natureza é o "filosofar puramente teórico (liberto de toda intervenção subjetiva e prática)". E o eu, como consciência consciente, é apenas o produto supremo de um desenvolvimento de potências, que tem início com o inteiramente objetivo ou real, mas que, como esse real também é ideal (sujeito-objeto), tem a tendência a se elevar progressivamente ao ideal: "com a filosofia-da-natureza, diz Schelling, eu nunca saio daquela identidade do ideal-real; eu conservo ambos continuamente nessa ligação originária, e o puro sujeito-objeto, do qual eu parto, é justamente esse simultaneamente ideal e real na potência 0 . Apenas a partir dele surge, para mim, o ideal-real da potência superior, o eu, em relação ao qual aquele puro sujeito-objeto já é objetivo" (ibidem, p. 91).

Desde o início, então, situando-se no ponto de vista do Absoluto, em que toda objetividade já está justificada, Schelling começa de pronto sua exposição do sistema-da-identidade com a definição da razão: a razão absoluta tem de ser pensada como a total indiferença do subjetivo e do objetivo (SCHELLING, 1976, I/10, p. 120), restando mostrar como nela está inscrito um Conhecer (ideal, subjetivo) e um Ser (real, objetivo), que, se originariamente um e o mesmo, aparecem, porém, como uma diferença quantitativa entre subjetividade e objetividade. Tal aparecer da indiferença como diferença quantitativa tem seu 
fundamento na tendência ao subjetivo ou à subjetivação igualmente inscrita nesse subjetivo-objetivo, na medida em que o subjetivo ou ideal limita progressivamente o objetivo ou real, tendo lugar uma crescente diferenciação da indiferença originária entre subjetivo e objetivo, na qual, por conseguinte, enquanto permanece na base a indiferença originária, aparece um desenvolvimento gradativo em série de potências, no qual cada potência se distingue das outras em virtude da preponderância do subjetivo ou do objetivo: magnetismo, eletricidade, processo dinâmico, mundo inorgânico e orgânico, etc. até a consciência consciente, o eu de que partiria a doutrina-da-ciência. Apesar desse diversificado aparecer (Erscheinung), no entanto, todas as potências são, sob o ponto de vista do Absoluto e em si, uma e a mesma identidade, pois apenas para o ponto de vista da consciência elas aparecem como diferentes. Como diz Schelling: "as coisas ou Erscheinungen, que nos aparecem como diferentes, não são verdadeiramente diferentes, mas realiter Uma, de tal modo que não cada uma por si, mas todas na totalidade, na qual originalmente as potências opostas se suprimem mutuamente, expõem a própria identidade pura e incólume. (...) A força, que se espraia na massa da natureza, é, segundo a essência, a mesma que a que se expõe no mundo espiritual, exceto que lá ela tem de lutar com a preponderância do real e aqui com a do ideal, mas mesmo essa oposição, que não é uma oposição segundo a essência, mas segundo a mera potência, aparece como oposição apenas àquele que se encontra fora da indiferença e não contempla a identidade absoluta como o originário" (ibidem, p. 123-4)9.

Portanto, é porque se encontra na totalidade e contempla o puro sujeito-objeto em seu produzir originário que Schelling pode apresentar o "sistema do saber", expor todo o agir inconsciente da razão (ou Absoluto), pôr, afinal, todos os pressupostos do saber e, com isso, explicar a própria filosofia transcendental: esta mesma é algo limitado, porque ainda se prende a um produto da razão - a consciência consciente -, não se eleva ao seu produzir originário, é incapaz assim de compreender a identidade originária entre subjetivo e objetivo (consciente e inconsciente) e, por isso, ainda está presa à aparência transcendental: ainda existem condições do saber que são tomadas por objetos do conhecimento e que estão fixadas nas oposições da reflexão, separando aquilo que originariamente e no ponto de vista da totalidade está unificado. É nestes termos, enfim, que podemos reencontrar a definição dada por Schelling para o ponto de vista da doutrina-da-ciência: "Fichte poderia ter pensado o idealismo em uma significação totalmente subjetiva, eu, ao contrário, em uma significação objetiva; Fichte poderia, com o idealismo, se manter no ponto de vista da reflexão, eu, ao contrário, teria me colocado com o idealismo no ponto de vista da produção" - que é exatamente esse ponto de vista da razão como totalidade, em que não há produtos, mas apenas o produzir.

Não é isso, contudo, o que pensa Fichte. As críticas de Schelling não só não atingem a doutrina-daciência, como, antes, decorrem de uma determinada leitura equivocada da filosofia transcendental. Fichte escreverá a Schad, no final de 1801, quando a ruptura entre os dois já era eminente: Schelling "nunca entendeu o meu sistema" (FICHTE, 1962, GA III/5, p. 101) ${ }^{10}$. Afinal, a doutrina-da-ciência surgiu e entrou em cena pela primeira vez justamente a partir da crítica a Reinhold e à sua proposição da consciência na qual a faculdade-de-representação é o primeiro princípio de todo saber. A Resenha de Enesidemo (1794) é, do começo ao fim, um recenseamento de problemas nos quais uma filosofia da representação - ou da reflexão, nos termos de Schelling - necessariamente cai, e que, caso não seja adotado um ponto de vista anterior e mais originário, levam ao ceticismo, tal como o de Enesidemo. Já ali, diz Fichte: "para toda 
filosofia, não meramente para a teórica, tem de haver ainda um conceito superior ao da representação" (FICHTE, 1962, GA I/2, p. 43).

Tendo recebido de Schelling seu Sistema do idealismo transcendental e a Exposição do meu sistema da filosofia, o descontentamento de Fichte é, por consequência, imediato; para ele, o mal-entendido é claro: Schelling não só não compreendeu a doutrina-da-ciência, como seu sistema-da-identidade só pode ser uma saída para problemas decorrentes dessa incompreensão. Não entender a doutrina-da-ciência, diz Fichte em carta a Schelling, de 01/1802, significa, antes de tudo, limitar seu princípio e todo seu domínio tão somente à consciência, interpretando, nessa medida, o "eu" apenas como uma atividade consciente, $o$ sujeito-objeto subjetivo, que, necessariamente, tem de aparecer como algo fixado e em oposição a um outro domínio, aquele do inconsciente ou sujeito-objeto objetivo (FICHTE, 1962, GA III/5, p. 111). Assim lendo, Schelling é levado equivocadamente à compreensão de que há uma cisão entre consciente (eu, espírito) e inconsciente (não-eu, natureza) - o pensamento e a extensão de Espinosa -, no fundamento da qual ter-se-ia de se encontrar, necessariamente, uma unidade. Na mesma carta a Schelling, Fichte escreve: "há um saber relativo, membro correlato (Nebenglied) do Ser. (...) Ora, você sempre encontrou a minha doutrina-da-ciência no ponto de vista desse Saber. O membro correlato desse Saber é o Ser supremo e, justamente por isso, absoluto - Ser, digo eu. Ora, você acredita ter se elevado ao conceito desse Ser, acima da doutrina-da-ciência, e unifica então os membros correlatos" (ibidem, p. 111-2). Ou seja, entendendo a doutrina-da-ciência como circunscrita ao domínio da consciência - aqui, Saber relativo - que tem diante de si a objetividade - aqui, o Ser correlato ao Saber relativo -, é preciso encontrar um fundamento comum a ambos, que os explique e os funde - um fundamento comum que seja ao mesmo tempo a identidade originária dos dois, da consciência - o subjetivo - e da não-consciência - o objetivo -, identidade que é justamente a indiferença entre subjetivo e objetivo, tal como ela aparece na definição inicial da razão na Exposição do sistema-da-identidade. Com essa identidade originária, Schelling crê, decerto, explicar os dois opostos e, como a filosofia transcendental se limita a um deles apenas, explicar esta também. Segundo Fichte, todavia, isso significa que Schelling, nessa unificação através da indiferença entre subjetivo e objetivo, pressupõe como algo já dado tanto a cisão bem como os seus próprios membros, de tal modo que a unificação, como em toda metafísica dogmática, teria antes o caráter de uma unificação post factum, do que realmente o caráter de uma unidade originária. Fichte continua: "se você vê apenas nisto o Ser mais absoluto que você pode estabelecer, então você encontra nele a clara característica de uma composição (Zusammensetzung), que, certamente, não pode ocorrer sem cisão; por isso, você deriva desse ser, também de modo correto, o saber (relativo) e, desse saber, novamente o ser" (ibidem, p. 112). Em outras palavras, é como se Schelling partisse do "subjetivo" (espírito) e do "objetivo" (natureza) como de dois domínios já dados, isto é, duas significações já objetivas, cuja cisão teria de ser suprimida por uma unificação.

Ora, essa interpretação de Fichte da compreensão de Schelling do idealismo transcendental faz jus a uma leitura rigorosa dos textos de Schelling. É o que mostra o Sistema do idealismo transcendental, justamente aquela obra na qual Schelling procura dar acabamento aos seus trabalhos sobre o idealismo que corriam em paralelo àqueles sobre a filosofia-da-natureza, expondo-os então em forma sistemática; uma obra, entretanto, que conduz Schelling a tais impasses que o obrigam a considerar o idealismo transcendental como um saber meramente preso ao ponto de vista da consciência e da reflexão, e que carece, por isso, de uma fundação mais originária através de uma filosofia-da-natureza, enquanto parte real do sistema-daidentidade. 
No Sistema ${ }^{11}$, Schelling parte da autoconsciência (o eu) como princípio e certeza primeira do idealismo transcendental, já que nela, de um lado, intuinte e intuído, representante e representado, são um e o mesmo, mas que, de outro, ao se efetuar como ato produz a duplicidade originária constituinte de toda inteligência entre ideal (intuinte, subjetivo) e real (intuído, objetivo). Partindo dessa duplicidade originária das atividades objetiva e subjetiva, Schelling procura explicitar todas as ações do eu pelas quais ele progressivamente se objetiva, isto é, torna-se para si mesmo objeto, quando então ele toma consciência de si mesmo como autoconsciência. Esse processo, pois, é a história das épocas da autoconsciência, na qual o eu inicial, que é objeto apenas para o filósofo, torna-se progressivamente objeto para si mesmo. Com efeito, no interior dessa dedução das épocas da autoconsciência, filosofia teórica e, depois, filosofia prática são derivadas como momentos necessários nesse processo de tomada de consciência do eu. Da dedução desses dois domínios, todavia, emerge uma contradição que tem de ser resolvida, pois do contrário não é possível pensar o agir prático da inteligência - uma contradição fundamental, já que o próprio Schelling designará a sua solução como a "tarefa suprema de toda filosofia" (SCHELLING, 1976, I/9, p. 38). A saber: se, na filosofia teórica, mostra-se como a representação concorda com o objeto e há aqui um predomínio do real sobre o ideal, e se, na filosofia prática, mostra-se como um objeto deve concordar com uma representação do querer, havendo, por conseguinte, um predomínio do ideal sobre o real, surge uma contradição entre as duas direções das concordâncias, como se com a certeza teórica se perdesse a prática e com a certeza prática se perdesse a teórica (cf. ibidem). Trata-se, pois, da contradição entre a necessidade do teórico e a liberdade do prático, que exige uma síntese necessária para se pensar o próprio agir do eu na realização completa da autoconsciência. Para tanto, diz: a liberdade deve ser necessidade, a necessidade deve ser liberdade; isso significa, o inconsciente deve ser igual ao consciente e vice-versa: pela liberdade deve surgir inconscientemente, sem minha intervenção, o que eu não tencionava, deve haver, pois, um engrenar de uma necessidade oculta na liberdade do eu que garanta a sua própria realização, decerto, não como indivíduo, mas como espécie na história. A história, nesse sentido, tem de possuir um plano prévio que apareça como uma síntese absoluta de todas as ações, a partir da qual tudo o que ocorre se desenvolve e é unificado para a realização de uma constituição universal cosmopolita. Como uma unidade sistemática de todas as ações, por conseguinte, essa história é concebida como uma harmonia entre o inconsciente e o consciente e, ao ser anterior ao próprio agir, como uma harmonia preestabelecida. Quer dizer, não seria possível pensar a síntese absoluta de ações, na qual necessidade e liberdade estivessem conjugadas, se em seu fundamento não houvesse uma harmonia das duas, na qual o agir que aparece como livre está conjugado em um plano anterior e inconsciente que trabalha para a sua realização: "como, ao mesmo tempo, o mundo objetivo se orienta segundo representações em nós, e representações em nós segundo o mundo objetivo, não é compreensível se não existe entre os dois mundos, o ideal e o real, uma harmonia preestabelecida" (ibidem).

Por sua vez, essa harmonia preestabelecida entre o teórico e o prático, o inconsciente e o consciente, só é pensável se em seu fundamento já se encontra uma identidade originária das duas atividades, dos dois domínios. Como diz Schelling: "uma tal harmonia preestabelecida do objetivo (legal) e do determinante (livre) só é pensável por algo superior, que está acima de ambos, que, portanto, não é nem inteligência [domínio do teórico, FPG] nem livre [domínio do prático, FPG], mas a fonte comum do inteligente e do livre ao mesmo tempo" (ibidem, p. 299). Um fundamento superior que, assim pensa Schelling, não é a soma dos dois, mas a fonte comum de ambos, que aqui, pela primeira vez, antes mesmo do sistemada-identidade, já aparece como identidade absoluta. Schelling continua: "se esse superior não é nada mais que o fundamento da identidade entre o absolutamente subjetivo e o absolutamente objetivo, o 
consciente e o inconsciente, que justamente em vista do aparecer (Erscheinung) no agir livre se separam, então esse superior não pode ser nem sujeito, nem objeto, nem mesmo ambos ao mesmo tempo, mas apenas a identidade absoluta, na qual não há nenhuma duplicidade e que, justamente porque a duplicidade é condição de toda consciência, não pode chegar à consciência” (ibidem). Tal identidade originária é concebida a partir de uma teleologia e se revela ao eu, especificamente, em duas espécies de produtos: na natureza orgânica e na obra do gênio, na arte. Nas duas há a unificação das atividades consciente e inconsciente: a primeira, enquanto atividade inconsciente, aparece como se fosse consciente - produtos finais sem serem produzidos finalmente (conscientemente); a segunda, enquanto atividade consciente, aparece como se fosse inconsciente, como se fosse natureza. Em ambos os casos, por conseguinte, é a teleologia que soluciona a contradição central emergida com as filosofias teórica e prática: "a filosofia dos fins naturais ou a teleologia é, portanto, aquele ponto de unificação da filosofia teórica e da prática” (ibidem, p. 39).

Não obstante, há de se perguntar em que sentido essa solução ainda permanece nos marcos do idealismo que o próprio Schelling estabeleceu no início do Sistema. Se a exposição deve ser sistemática, o seu primeiro princípio - a autoconsciência - tem de aparecer ao final como seu resultado. No entanto, não é isso o que se passa: a identidade originária que está no fundamento das duas atividades não é idêntica ao princípio do idealismo, a autoconsciência. Não é à toa que a arte, ao final de toda epopeia da autoconsciência, não é mais a expressão no eu da própria identidade sintética do eu - sua duplicidade originária -, mas da identidade originária: "a obra de arte reflete para mim somente o que, do contrário, não é refletido por nada: aquele absolutamente idêntico, que mesmo no eu já se separou; aquilo que o filósofo, já no primeiro ato da consciência, deixa se separar, é refletido (zurückgestrahlt) pelo milagre da arte a partir dos seus produtos, e que, do contrário, é inacessível para toda intuição” (ibidem, p. 325-6). Em outras palavras, o princípio do idealismo transcendental, tal como entendido por Schelling, não consegue resolver os seus próprios problemas e, por estes, se é impelido para fora desse princípio, para a afirmação de uma identidade originária do subjetivo e do objetivo, que, no fundo, torna possível o próprio eu, enquanto autoconsciência. Ora, é justamente essa identidade originária entre esses dois mundos, que, já no ano seguinte, aparecerá como a definição da razão: a indiferença entre o subjetivo e o objetivo, fundamento de todo o desenvolvimento do sistema-da-identidade. Já dados como dois polos do saber, a coincidência de subjetivo e objetivo terá de se apresentar a partir de um terceiro que está no fundamento dos dois - a identidade originária de uma e mesma atividade que é ao mesmo tempo consciente e inconsciente.

Ora, esse terceiro só é estabelecido em vista dos dois polos já dados, isto é, ele os pressupõe, de modo que essa identidade dos dois domínios: da consciência (eu) e da não-consciência (natureza), tem de ser pensada como posterior a eles, como os pressupondo, para unificá-los, então, em uma unidade superior. Nesse sentido, Schelling não está muito longe daquilo que Kant propõe através dos postulados práticos da razão. O problema, aliás, é o mesmo: a saber, estabelecer uma unidade sistemática que permita pensar o agir moral e a realização do Sumo Bem no mundo, na natureza. Ali também, em Kant, diante da pergunta: “o que me é permitido esperar?", era preciso pressupor que o mundo era governado por uma razão suprema, que conjugasse a natureza e as ações livres em uma unidade sistemática. Ali também, enfim, essa unidade sistemática era uma unidade final que era pensada a partir dos dois domínios, quer dizer, depois do seu estabelecimento. Traço característico, para Fichte, do ponto de vista da filosofia crítica, na qual natureza e liberdade já estão dadas e Kant simplesmente postula uma raiz comum suprassensível, porém inescrutável, onde, portanto, ainda se está no âmbito do fático, mas não do genético (FICHTE, 1986, 
p. 28-9), essa identidade originária do sistema-da-identidade é inevitavelmente, segundo Fichte, uma síntese post factum, já que é uma síntese posterior ao factum do saber. Daí então Fichte dizer a Schelling que sua identidade ou indiferença traz a marca da composição: a cisão dos dois domínios e a sua significação e determinação como consciente, subjetivo, de um lado, e inconsciente, objetivo, de outro, precisam ser pressupostas como dadas, e só a partir desses dados é possível estabelecer essa "identidade originária". Trazendo a marca da composição, essa identidade só pode ser relativa, isto é, se refere aos termos que ela identifica: Schelling "começa e diz: a razão é a absoluta indiferença entre sujeito e objeto. Ora, aqui tem de ser mostrado a ele, que ela não pode ser ponto absoluto de indiferença sem ser ao mesmo tempo ponto de diferença. Logo, que ela não é nenhum dos dois absolutamente, mas ambos são apenas relativamente" (ibidem, p. 141). Sendo uma unidade relativa, ela é, no fundo, apenas negativa: ela é indiferença. Fichte escreve a Schelling: você unifica os membros correlatos "não materialiter, por visão (Einsicht), mas formaliter, porque a carência do sistema é unidade, não por intuição (que teria de fornecer algo positivo), mas pelo pensar (que apenas postula uma relação) - em uma identidade negativa, isto é, não-diferença do saber e do Ser, em um ponto de indiferença" (FICHTE, 1962, GA III/5, p. 112 - "postula" grifo nosso). Enfim, unidade realizada pelo pensar, que, por sua vez, sempre estabelece uma relação entre termos, essa identidade traz a marca de uma projeção, isto é, algo captado pelo saber já fático, que se dá no interior do saber e segundo as suas leis de projeção, e, por conseguinte, só pode ser considerado um produto seu - e por aqui, já se começa a vislumbrar em que medida o sistema-da-identidade ainda está preso ao ponto de vista da consciência. Ele está preso à consciência, porque está preso ao seu ato de objetificação (à projeção): ele exterioriza, isto é, objetifica a razão, segundo as leis da consciência, nessa indiferença entre subjetivo e objetivo, na qual se explica a consciência consciente como produto final do processo de desenvolvimento da própria natureza, agora entendida como razão também. A solução da contradição entre o consciente e o inconsciente, afinal, se resolve em uma teleologia, que nunca deixa de ser uma certa representação ou concepção positiva das coisas. - Como escreve Fichte: "ele [Schelling] diz: a razão é; logo, ele aliena (entäussert) a mesma diante de si, coloca-a diante de si objetificando-a; de modo que ainda se tem de lembrá-lo de que com essa definição ele não encontrou a autêntica razão. Essa objetificação da razão não é, em parte alguma, o caminho correto. Na filosofia, não se trata de falar de fora sobre a razão, mas de praticar o ser-racional com toda a seriedade" (FICHTE, 1986, p. 141). Nisto Schelling comete o mesmo pecado de todo dogmatismo: colocar o Absoluto em uma "coisa", objetificar a razão ${ }^{12}$. Na exposição da doutrina-da-ciência de 1801/2, Fichte dirá, referindo-se explicitamente a Schelling: "essa visão da absolutez, esse saber do saber de si mesmo, e o que é inseparável disso, como absoluto, é a razão. O mero e simples saber, sem que ele se apreenda novamente como saber, é o entendimento. A segunda espécie de inteligência compreende, decerto, segundo as leis da razão, coagida a isso aliás, já que, do contrário, ela não poderia compreender e não seria nenhuma espécie de inteligência; portanto, ela tem razão, mas ela não apreende a razão. A razão dela não é interior e para si, mas está fora dela, na natureza e em uma admirável alma da natureza, que ela denomina Deus" (FICHTE, 1962, GA II/6, p. 212-3).

Nesse mesmo sentido, em outra carta, Fichte compara Schelling a Espinosa, declarando que Schelling, como Espinosa e todo dogmatismo, "vai imediatamente ao Absoluto com o seu pensar, sem se lembrar do seu pensar, isto é, sem considerar que esse Absoluto pode ser enformado (formiert) pelas leis imanentes do pensar" (FICHTE, 1962, GA III/5, p. 91). Em carta a Schad, Fichte será enfático quanto ao dogmatismo de Schelling: "e o que se deve dizer do seu novo - e transfigurado! - espinosismo, no qual ele, alegremente, deixa o Absoluto existir sob as formas da quantidade, como Espinosa também faz e todo dogmatismo? Pode alguém que conhece tão pouco a verdadeira fonte de todo o conceito da quantidade 
e, com ele, de toda multiplicidade, alguma vez ter sabido o que é o idealismo crítico? (FICHTE, 1962, GA III/5, p. 101). Assim como todo dogmatismo, Schelling deixa o Absoluto existir sob a forma do pensar, a forma da quantidade, mas nunca se pergunta como se dá a passagem do Absoluto para a quantidade $\mathrm{e}$ seus respectivos pontos de vista. Não sem razão, Fichte denominou essa questão, em carta a Reinhold, de 07/1795, de "questão-capital" de toda especulação (FICHTE, 1962, GA III/2, p. 345). É o que se repete nas diversas exposições da doutrina-da-ciência ${ }^{13}$. É também o que Fichte escreve a Schelling: se, decerto, o Absoluto aparece no saber sob uma forma, tem-se, porém, de perguntar: "de onde, contudo, vem a forma - em todo caso da quantidade, também sobre isso eu estou de acordo com você - sob a qual ele aparece (...) - ou também: como, pois, o Um se transforma primeiro em um infinito e, então, em uma totalidade do múltiplo" (FICHTE, 1962, GA III/5, p. 91). E a ignorância dessa questão será também a repreenda que Fichte fará a Espinosa, enquanto dogmático por excelência: ele tem o Um, a substância, que aparece multiplamente em seus acidentes (atributos), mas ele é incapaz de compreender como se dá a passagem da substância para os acidentes, do Um para o Tudo e vice-versa, e por isso, diz Fichte, "ele introduz as duas formas fundamentais do Absoluto, Ser e Pensar, sem dar nenhuma prova" e - continua Fichte: "como você também o faz" (FICHTE, 1962, GA III/5, p. 112). Por isso, referindo-se a essa questão-capital de toda especulação, arremata Fichte a Schelling: "essa é a questão que a especulação que vai até o fim tem de solucionar, e que, como você já encontra essa forma [forma da quantidade, FPG] no Absoluto e com ele ao mesmo tempo, você tem necessariamente de ignorar. Ora, aqui, em uma região, portanto, à qual você se fechou através do seu novo sistema, e que nunca foi conhecida por você, como agora se pode dizer com segurança, encontra-se o idealismo da doutrina-da-ciência e o kantiano: de modo algum, ali embaixo, onde você o localiza" (FICHTE, 1962, GA III/5, p. 91).

Ora, essa região emerge justamente quando consideramos o caráter discursivo da doutrina-da-ciência e do idealismo transcendental - caráter inédito, dirá Fichte (FICHTE, 1986, p. 9) ${ }^{14}$. Ao contrário do sistema-da-identidade de Schelling e de todo dogmatismo, a doutrina-da-ciência não se propõe ser um saber de objetos, muito menos um saber do Absoluto, como se fosse possível falar sobre o Absoluto. Afinal, isso seria considerá-lo no interior da forma do saber, portanto, sob suas leis e sob a forma geral de objetificação: ao Absoluto, "porque ele é o Absoluto - diz Fichte -, não há de se acrescentar nenhum predicado, nem o do Saber ou do Ser, tampouco o da Indiferença de ambos" (FICHTE, 1962, GA III/5, p. 102). Antes, a doutrina-da-ciência é um saber de todo saber, uma doutrina do saber em geral, que refletirá sobre a gênese e origem do saber, esgotando toda a sua forma, para assim entender como o Absoluto pode se apresentar sob essa forma e quais domínios são constituintes dessa forma - só então sendo possível falar em "natureza" e "espírito", "subjetivo" e "objetivo". Se, pois, esse proceder da razão é conhecido em todas as suas leis e figuras, é possível à doutrina-da-ciência neutralizar a eficácia do ato de objetificação, aniquilá-lo, para que então o Absoluto não esteja mais envolto na aparência, enquanto "coisa", não mais se o tenha ou se discurse sobre ele, mas que se viva o Absoluto. Nesse sentido, aliás, a doutrina-da-ciência desempenha um papel catártico ou purificador, de fazer o saber criticar-se a si mesmo, para que seu ato de objetificação não mais o iluda, não mais "coisifique" o Absoluto.

É, pois, no interior dessa constelação, a partir do projeto transcendental, que se deve compreender o tal do "eu absoluto" da doutrina-da-ciência, que tantos mal-entendidos causou, inclusive o rompimento da amizade entre Fichte e Schelling. Se há saber de objetos e verdade em geral, independentemente de 
qual seja esse saber, é preciso que o saber esteja fundado em um princípio absoluto que funde a si mesmo, do contrário não seria possível falar em verdade, mas tudo seria relativo: uma proposição estaria fundada em outra, que estaria fundada em outra e assim ao infinito - não haveria um fundamento último do saber que daria a ele unidade e objetividade. Ora, o saber para Fichte, assim como para Schelling, se define especificamente pelo seu caráter genético, a partir do qual se mostra que o saber é sempre o reconhecimento daquilo que ele próprio já produzira - nisto, aliás, ambos levam ao extremo o lema kantiano de que: "a razão só compreende aquilo que ela mesma produz segundo seu projeto" (KANT, 1968, III, p. XIII). Sem produção do objeto, não há inteligibilidade dele, não há saber. Assim, se, de um lado, admite-se que há saber e verdade, e se, de outro, o saber se caracteriza pela gênese e pelo seu caráter de produção, então no fundamento do saber tem de se encontrar uma gênese absoluta, o que significa precisamente: um agir que produz a si mesmo. Ao contrário de toda outra posição predicativa e mesmo de toda posição predicativa em geral, na qual há sempre uma distância entre sujeito e predicado - "algo como algo" -, esse agir sobre si mesmo que produz a si mesmo tem de ser uma "posição" que encontra sua verdade em si mesma, a partir de si mesma e por si mesma, onde, portanto, não há hiato entre sujeito e predicado (objeto) - é uma posição absoluta: o eu "é ao mesmo tempo o agente e o produto da ação; o ativo e aquilo que é produzido pela atividade; ação (Handlung) e feito (Tat) são um e o mesmo" (FICHTE, 1984, p. 46). Daí Fichte batizar o primeiro princípio de todo saber de Tathandlung, cuja expressão justamente é a proposição $e u$ $s o u^{15}$. Nesta não se trata de uma proposição sobre um determinado fato ou mesmo a constatação de um fato da consciência - não é um saber de algo -, mas é a expressão de uma produtividade originária que produz a si mesma como produtividade, onde, portanto, não há distância nenhuma entre produção e produto, entre ser e pôr - "o eu põe a si mesmo e é, em virtude desse mero pôr-se por si mesmo; e viceversa: o eu é e, em virtude de seu mero ser, põe seu ser” (ibidem). A Tathandlung, em suma, é expressão de uma gênese absoluta: uma ação que faz a si mesma; ela expressa, nesse sentido, o núcleo duro interno de toda racionalidade em geral, independentemente de qualquer objeto e coisa conhecida; nela, portanto, há transparência plena e, por isso, é fundamento de todo outra posição e de todo outro agir da razão ${ }^{16}$. Como diz Fichte, na primeira exposição da doutrina-da-ciência (1794/5), acerca do eu absoluto: "sua atividade inteira vai ao eu e essa atividade é o fundamento (Grund) e o âmbito (Umfang) de todo ser. Infinito, portanto, é o eu na medida em que sua atividade retorna a si mesma, e nessa medida, pois, também sua atividade é infinita, porque seu produto, o eu, é infinito. (Produto infinito, atividade infinita; atividade infinita, produto infinito; isto é um círculo, que, porém, não é vicioso, porque é o círculo de que a razão não pode sair, já que por ele é exprimido aquilo que é certo pura e simplesmente por si mesmo e em virtude de si mesmo" (FICHTE, 1984, p. 138 - parte final grifo nosso). Quer dizer, a Tathandlung não é uma verdade material ou a constatação de um fato da consciência, mas, por ser gênese absoluta, é pura e simplesmente a essência mais íntima de toda verdade. Fichte dirá em 1804: "saber puro em e para si, por isso saber de nada ou, caso a seguinte expressão devesse lembrá-los melhor, (...) verdade e certeza em e para si, que não é a certeza de algo, na medida em que, através disso, já seria posta a disjunção entre Ser e saber" (FICHTE, 1986, p. 14).

Anterior, portanto, a toda consciência e a todo eu empírico, a Tathandlung está no fundamento de todo saber, logo, de toda consciência, e é, pois, sua condição de possibilidade. Daí que, quando Fichte denomina esse primeiro princípio do saber de "eu absoluto", ele não visa com esse conceito uma consciência consciente ou um subjetivo que estaria em contraposição a um objetivo, tal como pensava Schelling e uma boa parte dos intérpretes mais modernos da doutrina-da-ciência ${ }^{17}$. Na verdade, a referência que mais vem à tona na Fundação de toda a doutrina-da-ciência (1794/5) para qualificar esse "eu" enquanto "eu 
absoluto" é a de "sujeito absoluto"; é o que diz a própria definição do "eu" formulada por Fichte nesse $\mathbb{S} 1$ : "isso torna, pois, plenamente claro, em que sentido usamos aqui a palavra eu e nos conduz a uma definição do eu, como sujeito absoluto. Aquilo cujo ser (essência) consiste meramente nisto: que ele põe a si mesmo como sendo é o eu, como sujeito absoluto" (FICHTE, 1984, p. 46). É sujeito absoluto na medida em que ao produzir a si mesmo é porque é e é o que é, sem nenhuma razão anterior a si mesmo; é, pois, o absolutamente determinante de todo saber e, por isso, está no fundamento de toda determinação sua, já que está no fundamento de toda consciência empírica - como se ele produzisse absolutamente seu objeto e tivesse consciência completa do produzido, isto é, transparência absoluta. E se, posteriormente, Fichte abandona o termo "eu absoluto" para designar a gênese absoluta, passando a chamá-la de "Ser absoluto", "Absoluto" ou "Vida" e mesmo "Deus", o que muda é somente o nome, a letra, porque o que está sendo ali expresso permanece o mesmo, a saber, uma gênese absoluta que, anterior a toda verdade material e a toda consciência fática, é condição última de toda verdade, já que exprime a essência mais íntima de toda racionalidade ${ }^{18}$. Como diz Fichte em carta a Schelling, de 05-08/1801: "se se quiser chamar isso que permanece impenetrável a esse olhar, Ser e, aliás, o absoluto, então Deus é o Ser puro; esse Ser, porém, é em si não compressão, mas é inteiramente agilidade, pura transparência, Luz" (FICHTE, 1962, GA III/5, p. 48$)^{19}$.

Todavia - e isso é fundamental -, enquanto agir que produz a si mesmo, o eu absoluto (ou o Absoluto) está fechado em si mesmo, ele é tudo em tudo e, por isso, não é nada para si, isto é, ele não tem nenhum outro conteúdo que si mesmo, logo, não há nele ainda nenhum saber de algo. Para haver saber, o eu tem de sair de si mesmo e como que abrir-se para o advento da multiplicidade (do não-eu). É aqui, pois, que entra em cena a dita "questão-capital" pela passagem do Absoluto para o múltiplo, para a quantidade e a forma em geral do saber através da qual ele aparece. Na carta a Reinhold já citada, Fichte escreve: "se o eu originalmente põe apenas a si mesmo, como ele chega, pois, a pôr ainda algo outro, como oposto a ele, e sair de si mesmo?" (FICHTE, 1962, GA III/2, p. 345). Seja sob o nome de imaginação, quantitabilidade ou do mediante (Durch), essa forma do saber será entendida sobretudo como uma reflexão do eu sobre si mesmo, pela qual ele deve apreender a si mesmo como infinito, isto é, como realizando a gênese absoluta. Como, todavia, essa reflexão é uma forma - a quantitabilidade ou determinação em geral - alheia e refratária à gênese absoluta, na medida em que é impossível ser infinito na forma da reflexão, isto é, como objeto do saber, já que todo objeto traz consigo a determinação e, com ela, a finitude (a negação da gênese), introduz-se com ela a cisão entre sujeito e objeto: a gênese não se realiza na forma do saber, mas permanece uma exigência, já que sem o fundamento absoluto do saber (a gênese absoluta) não há saber algum. É somente aqui, portanto, na passagem do Absoluto para a forma na qual ele aparece, nessa cisão e disjunção entre o reflexionante e o refletido, que tem início a consciência e de onde, consequentemente, surgem as significações "subjetivo": o eu divisível (quantificável), como acidente do oscilar da imaginação; e "objetivo": o não-eu divisível (quantificável), também como acidente do oscilar. Lemos, na primeira exposição da doutrina-da-ciência: "o próprio eu é reduzido a um conceito inferior, o da divisibilidade, para poder ser igualado ao não-eu; e no mesmo conceito é-lhe também oposto. (...). Eu e não-eu, na medida em que são igualados e opostos pelo conceito da limitabilidade mútua, são ambos algo (acidentes) no eu, como substância divisível; posto pelo eu como sujeito absoluto, ilimitável, ao qual nada é igual e nada é oposto" (FICHTE, 1984, p. 60) ${ }^{20}$. E não se trata aqui da consciência tal como a pensa Schelling, como consciência consciente, que também para Fichte é um produto bem tardio da "história pragmática do espírito humano", mas se trata dela, antes de tudo, como forma em geral, na qual todo saber aparece. Lembremos que a imaginação (ou o mediante (Durch), na exposição de 1804) é um oscilar entre eu e não- 
eu na forma da substancialidade, o que significa, de acordo com a definição de substancialidade de Fichte, que o ponto de apoio do oscilar não pode ser nem o eu nem o não-eu, pois, enquanto acidentes, eles são o que é refletido, sendo a substância o próprio oscilar - aliás, a fixação unilateral em um desses acidentes dá justamente os pontos de vista unilaterais dos idealismos e realismos dogmáticos, sendo a doutrina-daciência não uma determinada perspectiva, mas a explicação de todo ponto de vista possível. Ademais, isso também significa que o eu consciente já é um refletido e, por consequência, algo produzido por esse oscilar, isto é, um produto dele. Logo, só depois de explicada a passagem da atividade infinita indeterminável para o oscilar da forma do saber através da reflexão sobre si mesmo, forma sob a qual essa atividade infinita originária aparece, e portanto, só depois de dada a gênese das significações "subjetivo" e "objetivo", é possível falar de um "espírito" e de uma "natureza", como domínios do saber. Em resumo, termos como "moral", "direito", "religião" e "natureza", assim como "subjetivo" e "objetivo", só têm significação a partir da forma do saber, sendo, pois, seus produtos ${ }^{21}$.

Nessa configuração, portanto, a doutrina-da-ciência não é um ponto de vista, mas a doutrina dos pontos de vista e da gênese dos domínios do saber. Aliás, essa concepção da doutrina-da-ciência de uma ciência do saber em geral e, por conseguinte, de todos os seus domínios e dos princípios das ciências particulares, já está presente desde a sua primeira definição no escrito programático Sobre o conceito da doutrina-da-ciência (1794). Ali, Fichte diz que cabe à doutrina-da-ciência expor as ações necessárias do espírito humano, pelas quais torna-se possível o saber; no interior dessa dedução das ações necessárias, são explicitados os domínios e as ciências particulares, enquanto partes do saber humano em geral. A diferença entre a doutrina-da-ciência e uma ciência positiva particular consiste em que a primeira expõe o agir necessário, enquanto a segunda é a determinação desse agir necessário a partir de um agir livre. E o exemplo que Fichte dá dessa diferença na maneira da consideração é justamente um exemplo da natureza e da ciência da natureza, como que já antecipando possíveis problemas futuros: "pela doutrina-da-ciência está dada, como necessária, uma natureza a ser considerada, segundo seu ser e suas determinações, como independente de nós - e as leis segundo as quais ela deve e tem de ser necessariamente observada: mas, com isso, o Juízo conserva sua plena liberdade de em geral aplicar essas leis ou não; ou, na multiplicidade das leis, assim como dos objetos, aplicar a lei que quiser ao objeto que preferir, por exemplo: considerar o corpo humano como matéria bruta ou organizada, ou como matéria animada" (FICHTE, 1984, p. 25). Ao pretender deduzir todo saber a partir da identidade originária, Schelling não só já pressupõe a natureza como tal domínio do saber, ou como possuindo uma tal significação, como também acaba por dissolver toda diferença entre filosofia e ciência, retomando a velha pretensão dogmática da metafísica pré-crítica de ser um saber universal material ${ }^{22}$.

Ao contrário das críticas de Schelling, portanto, a doutrina-da-ciência não é uma filosofia da reflexão, que estaria presa ao ponto de vista da consciência e deduziria apenas o que é concebido por essa consciência consciente. Na verdade, na medida em que Schelling explica a razão como uma identidade absoluta que, do seu grau zero, enquanto sujeito-objeto objetivo, se eleva progressivamente ao sujeitoobjeto subjetivo, é ele quem admite como algo já dado o "subjetivo", o "objetivo" e o próprio saber, cuja diferença é meramente de grau, restando, pois, entender como esse progressivo desenvolvimento é uma gradação do subjetivo a partir do puramente objetivo. Por não compreender a gênese das significações "subjetivo" e "objetivo", "espírito" e "natureza", e por conseguinte, por estar preso às leis do pensar, Schelling é levado a projetar a forma do saber no Absoluto, que, enquanto total indiferença entre subjetivo e objetivo, só é concebível sob a pressuposição da significação dos termos próprios a essa forma. Nesse 
sentido, a unidade do sistema-da-identidade é uma unidade projetada, que, portanto, está presa à forma da objetificação de toda consciência. São proféticas as palavras de Fichte, quando ele critica Espinosa, pois já se vislumbra ali a mesma crítica a Schelling: "na realidade, sua suprema unidade não é outra senão a da consciência, e não pode ser outra, e sua coisa é o substrato da divisibilidade em geral ou a substância suprema, em que ambos, o eu e o não-eu (a inteligência e a extensão de Espinosa) estão postos. Longe de ultrapassar o eu puro absoluto, o dogmático nem sequer se eleva até ele; chega, quando vai o mais longe possível, como no sistema de Espinosa, até nosso segundo e terceiro princípio, mas não até o primeiro pura e simplesmente incondicionado" (FICHTE, 1984, p. 61). Portanto, cabe ao sistema-da-identidade de Schelling, e não à doutrina-da-ciência, a designação de "filosofia da consciência", pois preso ao modo de proceder da consciência, ao seu ato de objetificação, ele estabelece uma unidade no interior do saber e, portanto, como seu produto - com isso, Schelling ainda está preso à aparência transcendental, tal como desvelada por Kant, à qual ele justamente queria fugir: a total indiferença de subjetivo e objetivo não deixa, no limite, de possuir o caráter de um algo, de uma "coisa", produto do saber, quando o que está em questão é a sua explicação.

Ao colocar a questão-capital pela gênese do saber e pelo ponto de passagem do Absoluto para a forma do saber em que ele aparece, a doutrina-da-ciência é uma reflexão do saber sobre si mesmo, que por isso, está em condições de expor o Absoluto não como algo, mas como o agir que está no fundamento de todo saber e de toda afirmação sobre algo - é uma certeza absoluta; ela está, além disso, em condições de esgotar a forma do saber e, daí, deduzir as significações "subjetivo" e "objetivo", "espírito" e "natureza", elucidando, com isso, a própria filosofia-da-natureza. Tudo isso, porém, só vem à tona, quando a forma da consciência e seu ato de objetificação são aniquilados, para que nada de fático contamine a dedução genética daquilo que aparece à consciência. Tal se dá justamente através da reflexão e da abstração do filósofo que aniquila e esvazia todas as determinações fáticas do saber. - É só então, quando toda suposta objetividade é neutralizada em sua aparência e em sua nulidade, que é possível vir à luz toda a realidade que está no fundamento do saber, que o torna saber e que o anima, e que a todo dogmatismo fica oculta, na medida em que justamente todo dogmatismo é a objetificação dessa realidade em uma "coisa". Aqui, encontramos um sentido inédito para o termo "filosofia da reflexão", que cabe bem à doutrina-da-ciência: ela o é, porque, através da reflexão, aniquila toda aparência e mostra a nulidade da forma da consciência na afirmação do Absoluto: "a doutrina da ciência captou a tarefa posta à humanidade pela descoberta kantiana, na medida em que mostrou o que é o saber absolutamente em sua unidade, sabendo, de modo seguro, que dessa unidade resultam por si os seus ramos, que a partir dela poderiam ser caracterizados nós queremos aqui, por isso, retirar da realidade toda forma e indicar, pelo conhecimento da nulidade da forma, a verdadeira realidade no fundamento" (FICHTE, 1962, GA II/6, p. 129-30). E isso contra todo dogmatismo, inclusive o de Schelling, que justamente, objetiva o Absoluto em uma "coisa", que, como tal, é sempre sem vida: "em relação ao ser morto anteriormente estabelecido [pela metafísica dogmática, FPG], ficaria claro que ele não é, de modo algum, o Absoluto, mas somente o último produto da vida verdadeiramente absoluta que entrou na forma do eu; o último: portanto, aquilo no que, nessa forma, a vida está encerrada, apagada e exterminada, logo, não restando nele nenhuma realidade” (ibidem, p. 132).

Diante das críticas de Schelling contra a doutrina-da-ciência, cabe a esta, portanto, a última palavra: enquanto ciência de toda ciência, a doutrina-da-ciência é mais originária que toda outra ciência, inclusive a filosofia-da-natureza. - Fichte escreve, enfim, ao "filósofo da natureza": "as perguntas, se a doutrina-daciência toma o saber subjetiva ou objetivamente, se ela é idealismo ou realismo, não têm nenhum sentido; 
pois essas distinções são feitas apenas no interior da doutrina-da-ciência, não fora dela e antes dela; e sem a doutrina-da-ciência, elas permanecem também ininteligíveis. Não há nenhum idealismo particular, ou realismo, ou filosofia-da-natureza e tais, que seriam verdadeiros; mas em toda parte só há uma ciência, esta é a doutrina-da-ciência, e todas ciências restantes são apenas partes da doutrina-da-ciência, e são verdadeiras e evidentes apenas na medida em que repousam sobre o seu solo" (FICHTE, 1962, GA III/5, p. 45-6).

\section{NOTAS}

1. Mais adiante, no mesmo prefácio, Schelling escreve: "Para apreender em seu íntimo o sistema absoluto da identidade, que eu estabeleço aqui e que se afasta totalmente do ponto de vista da reflexão, já que esta parte apenas de oposições e repousa nelas, é extremamente útil conhecer exatamente o sistema-da-reflexão, ao qual aquele está oposto” (SCHELLING, 1976, I/10, p. 115).

2. Tal é o caso de leituras como a de Richard Kroner, por exemplo, em seu Von Kant bis Hegel, (KRONER, 1977).

3. Tal é o caso de Guéroult (GUÉROULT, 1930 - cf. 1a Parte, p. 261, e 2a Parte, pp. 6-39) e, mais recentemente, de Hühn (HÜHN, 1992, p. 107) e Traub (TRAUB, 2000, p. 126). Mesmo Dieter Henrich acaba não escapando a esse esquema de interpretação. Ele confunde a estrutura geral do saber - que é, sim, a autoconsciência, mas que para isso se configura em um conjunto de momentos - com o próprio princípio da doutrina-da-ciência, e como ele não encontra a autoconsciência no primeiro princípio, ele será levado a pensar que Fichte teria "evoluído" em suas exposições, chegando enfim à afirmação de um Ser absoluto que seria a base da autoconsciência (HENRICH, 1967). Para uma crítica desse esquema interpretativo e da leitura evolucionista da doutrina-daciência, ver sobretudo TORRES FILHO, 1975.

4. Quem primeiro chama a atenção para o caráter modelar da leitura de Schelling é Pareyson. Vale a pena ver: PAREYSON, 1976, sobretudo pp. 14-24. Para um comentário elucidativo da relação entre Fichte e Schelling em torno da ruptura de ambos, vale a pena ver ZÖLLER, 2006.

5. Para uma análise detalhada e distanciada do percurso de Schelling a partir de sua relação com Fichte, vale a pena ver GÖRLAND, 1973.

6. "Como o oposto da filosofia transcendental, a filosofia-da-natureza está separada da última na medida em que ela põe a natureza como autônoma (não, decerto, na medida em que ela é produto, mas na medida em que ela é ao mesmo tempo produtiva e produto)", ibidem, p. 30 .

7. Como diz o próprio Reinhold: “a ciência que, portanto, tem de preceder a metafísica e fundar seu primeiro princípio, não pode ser outra que a teoria da faculdade-de-representação, como aquela ciência na qual a representabilidade, na medida em que ela não é propriedade dos objetos representados, não é predicado metafísico, mas está fundada na faculdade do sujeito representante, é investigada e desenvolvida" (REINHOLD, 2003, p. 94-5). Tal como formulado por Reinhold, já se vê que esse princípio da representação tem sua sede precisamente na consciência: "a representação é, na consciência, distinguida do representado e do representante e referida a ambos" (REINHOLD, 2003, p. 98); e é tendo em mãos esse princípio que Reinhold terá de afirmar que todo restante saber tem de ser derivado da faculdade-de-representação e da representabilidade em geral: "as formas da faculdade-de-desejar são determinadas, em relação àquilo que nelas é a priori, apenas pela forma da faculdade-de-representação; a possibilidade de desejar depende da possibilidade de representar; e o conceito da razão prática só pode ser derivado do conceito da razão em geral e, logo, não sem o auxílio do conceito da razão teórica” (ibidem, p. 95).

8. Para um comentário bem esclarecedor do conceito schellinguiano de "passado transcendental", ver HÜHN, 1992, p. 22-34.

9. É dessa forma, aliás, que o sistema-da-identidade se apresentará como o sistema do saber exposto em três partes: uma parte puramente teórica e realista: a filosofia-da-natureza; uma parte prática e idealista: a filosofia transcendental - que, justamente, apenas entra em cena depois que o sujeito-objeto se elevou à consciência através do querer - e que, por isso, só possui uma prova prática; e, por fim, uma terceira parte real-idealista que, como unificação das duas anteriores, é a filosofia da arte.

10. Por aqui já se vê o quão aleatório são as leituras que dizem que Schelling teria levado Fichte a mudar sua doutrina de modo substancial, passando de uma filosofia da subjetividade para uma filosofia do Ser absoluto. Schelling nem mesmo compreendeu a dita "primeira” filosofia de Fichte. Tal é a interpretação de Guéroult, Hühn e Traub, como já dito. Ainda veremos quão equivocado 
é interpretar a primeira exposição da doutrina-da-ciência como uma filosofia da subjetividade.

11. Assim denominaremos o Sistema do idealismo transcendental de Schelling. Faremos aqui uma análise breve e dirigida, tendo em vista unicamente ilustrar a interpretação fichteana da compreensão schellinguiana do "idealismo transcendental". O leitor nos perdoe o caráter quase alusivo da análise.

12. Fichte dirá na segunda conferência da exposição da doutrina-da-ciência de 1804: "tanto quanto resulta de todas filosofias até Kant, o Absoluto foi posto no Ser, na coisa morta como coisa; a coisa deveria ser o Em-Si. (Eu posso acrescentar, de passagem, que mesmo desde Kant se permaneceu, exceto na doutrina-da-ciência, em toda parte e sem exceção nos supostos kantianos, bem como nos supostos comentadores e continuadores da doutrina-da-ciência, no mesmo Ser absoluto, e Kant não foi compreendido em seu verdadeiro princípio, sem dúvida, não enunciado por ele em nenhum lugar)” (FICHTE, 1986, p. 10).

13. Por exemplo, na exposição de $1801 / 2$ : "a questão-capital permanece sempre aquela pelo fundamento originário da multiplicidade” (FICHTE, 1962, GA II/6, p. 278).

14. Sobre esse caráter discursivo da doutrina-da-ciência, remetemos ao trabalho de Torres Filho, ao nosso ver definitivo quanto a esse ponto, sobretudo seu terceiro capítulo (ver TORRES FILHO, 1975).

15. Neste ponto, vale a pena conferir as análises de I. Thomas-Fogiel sobre essa proposição, nas quais ela mostra de modo original e instigante como nessa proposição o ato de fala e seu conteúdo são um e o mesmo: THOMAS-FOGIEL, 2000, por exemplo p. 76: "no primeiro princípio, e somente nele, o conteúdo do enunciado e o ato da enunciação são idênticos. É um ato cuja efetuação implica a existência não como coisa nem como estado, mas antes como ato. $\mathrm{O}$ primeiro princípio é verdadeiro de maneira imediata e irrecusável, porque é o único enunciado no qual o fato da enunciação e o conteúdo do enunciado são estritamente idênticos. Em toda outra proposição, introduz-se uma distância entre o sujeito que profere a proposição e o objeto da proposição".

16. O próprio Fichte dirá na exposição da doutrina-da-ciência de 1804 que a doutrina-da-ciência "põe no fundamento, em alemão, (...) uma Tathandlung, o que eu, nestas conferências, designei com a palavra grega Genesis, que em geral é mais bem compreendida do que a palavra alemã” (FICHTE, 1986, p. 136).

17. Tais como Guéroult, Traub, Hühn e Henrich, para retomar os autores já citados no início do texto.

18. Atribuir à mudança de nomenclatura uma mudança doutrinal parece ter sido, em boa medida, o destino da interpretação da doutrina-da-ciência de Fichte. A formulação mais clara dessa leitura é a de Guéroult, mas é também a de Henrich, e mesmo Lauth assume esse ponto de vista, ao dizer que a partir de 1801/2 Fichte passa a adotar uma doutrina do absoluto e uma doutrina do seu aparecer (Erscheinung), algo não encontrado nas exposições anteriores, já que, tomada como uma consciência ou uma autoconsciência consciente, mas nunca como um Absoluto, a Tathandlung tem de ser reconduzida à intelecção do Absoluto (LAUTH, 1983, p. 152). Como já dito, todavia, o primeiro a formular essa leitura de mudança doutrinária foi Schelling; cf. SCHELLING, 1965, III, pp. 595-720.

19. Na exposição de 1804, Fichte escreve: "não se trata do modo como é chamado esse Ser, mas de como se apreende e se mantém ele internamente” (FICHTE, 1986, p. 10).

20. É assim que, por exemplo, lemos na exposição de 1801/2: "o que mantém o saber estável e não deixa ele desfazer-se entre as mãos é apenas aquela determinação [do Ser absoluto]; por sua vez, apenas através dessa quantitabilidade aquela determinação pode ser vista - porque essa quantitabilidade, e só ela, é justamente o olho" (FICHTE, 1962, GA II/6, p. 110). E na exposição de 1804: "se a Vida vive no mediante (Durch), então ela vive como realidade absoluta, mas - como ela está no mediante - justamente apenas no mediante e enquanto mediante. Reflita-se agora o que se segue disso, se a única realidade absoluta, a ser vivida apenas imediatamente, entra na forma do mediante absoluto. Eu deveria pensar o seguinte: (...) que a conhecida divisibilidade infinita, em toda continuidade, surge como o fenômeno fundamental de todo nosso saber - em uma palavra: isso que a doutrina-da-ciência denomina quantitabilidade, enquanto forma inseparável do aparecer (Erscheinung) da realidade" (FICHTE, 1986, p. 104).

21. Daí o equívoco em designar a "primeira" filosofia de Fichte de filosofia da "subjetividade" ou "idealismo subjetivo". Afinal, falar em subjetivo só é possível depois que a forma do saber foi deduzida e exposta, o que, no caso da exposição de 1794/5, só tem lugar com a exposição da imaginação. Em suma, o eu absoluto de que parte a doutrina-da-ciência não pode ser considerado um subjetivo porque ele é anterior à emergência de algo que pode ser designado "subjetivo".

22. Sobre essa pretensão dogmática de Schelling, que ele comunga com toda metafísica clássica pré-kantiana, e de como ela se 
confronta com a doutrina-da-ciência de Fichte, vale a pena ver WAIBEL, 2005.

\section{REFERÊNCIAS}

FICHTE, J. G. 1962ss. Gesamtausgabe der Bayerischen Akademie der Wissenschaften. Hrsg. von R. Lauth und H. Jacob. Stuttgart/Bad-Cannstatt: Frommann-Holzboog (abreviado como GA). . 1984. A doutrina-da-ciência de 1794 e outros escritos. Trad. de Rubens Rodrigues Torres Filho. São Paulo: Abril Cultural. 1986. Die Wissenschaftslehre: Zweiter Vortrag im Jahre 1804. Hamburg: Felix Meiner.

GÖRLAND, I. 1973. Die Entwicklung der Frühphilosophie Schellings in der Auseinandersetzung mit Fichte. Frankfurt a. M.: V. Klostermann.

GUÉROULT, M. 1930. Lévolution et la structure de la Doctrine de la Science chez Fichte. Paris, Strasbourg: Les Belles Lettres, Faculté de Lettres de l’Univ. de Strasbourg.

HENRICH, D. 1967. Fichtes ursprüngliche Einsicht. Frankfurt a. M.: V. Klostermann.

HÜHN, L. 1992. Fichte und Schelling oder: Über die Grenze menschlichen Wissens. Stuttgart: Metzler.

KANT, I. 1968. Kants Werke - Akademie Textausgabe. Berlin: Walter de Gruyter.

KRONER, R. 1977. Von Kant bis Hegel. Tübingen: Mohr.

LAUTH, R. 1983. "Die Verschränkung der Evidenzbegründung gneseologischer Wissenslehre und ontologischer Aussage im transzendentalen System”. In: HENRICH, D. (Hrsg.). Kant oder Hegel - Über Formen der Begründung in der Philosophie. Stuttgart: Klett-Cotta.

1998. Die Entstehung der Schellings Naturphilosophie in Auseinandersetzung mit Fichte.

Hamburg: Felix Meiner.

PAREYSON, L. 1976. Il sistema della libertá. Milano: Mursia.

REINHOLD, K. L. 2003. "Über das Bedürfnis, die Möglichkeit und die Eigenschaften eines allgemeingeltenden ersten Grundsatzes der Philosophie”. In: Beiträge zur Berichtigung bisheriger Missvertändnisse der Philosophen - Erster Band. Hamburg: Felix Meiner.

SCHELLING, F. 1976. Historisch-kritische Ausgabe. Hrsg. von W. G. Jacobs, J. Jantzen und W. Schieche. Stuttgart/Bad-Cannstatt: Frommann-Holzboog. . 1965. Schellings Werke. Hrsg. von Manfred Schröter. München: C. H. Beck.

THOMAS-FOGIEL, I. 2000. Critique de la représentation. Étude sur Fichte. Paris: J. Vrin. 
TORRES FILHO, R. R. 1975. O espírito e a letra. Crítica da imaginação pura em Fichte. São Paulo: Ática. TRAUB, H. 2000. "Schellings Einfluss auf die WL 1804. Oder: 'Manche Bücher sind nur zu lange geratene Briefe'”. In: Fichte-Studien, vol. 18, Amsterdam-Atlanta: Rodopi.

ZÖLLER, G. 2006. “Fichte, Schelling und die Riesenschlacht um das Sein”. In: BAUMANN, U. (Hrsg.) Fichte in Berlin - Spekulative Ansätze einer Philosophie der Praxis. Hannover: Wehrhahn. 